(2) Open Access Full Text Article

\title{
Hemiretinal vein occlusion with macular hemorrhage and edema treated with intravitreal bevacizumab
}

This article was published in the following Dove Press journal:

Clinical Ophthalmology

13 October 2011

Number of times this article has been viewed

\section{Shalini Yalamanchi Harry W Flynn Jr.}

Department of Ophthalmology, Bascom Palmer Eye Institute, Miami Miller School of Medicine Miami, FL, USA
Correspondence: Shalini Yalamanch Bascom Palmer Eye Institute, 900 NW 17th Street, Miami, FL 33।36, USA

$\mathrm{Tel}+\mathrm{I} 3053266000$

Fax + I 3053266417

Email syalamanchi3I@hotmail.com
Abstract: A 39-year-old male with decreased visual acuity and extensive macular hemorrhage and edema secondary to a hemiretinal vein occlusion was treated with multiple intravitreal injections of bevacizumab $1.25 \mathrm{mg}$ every four to six weeks for over one year. Treatment outcomes were assessed by visual acuity and Cirrus spectral domain optical coherence tomography. Treatment resulted in ongoing visual and anatomic improvement, with resolution at the last visit.

Keywords: retinal vein occlusion, macular edema, bevacizumab

\section{Introduction}

Retinal vein occlusions are a frequent cause of visual loss, and approximately 16 million adults worldwide are affected. ${ }^{1}$ Macular edema and retinal ischemia are the primary sources of visual impairment in these settings. Retinal vein occlusions can be classified as branch retinal vein occlusion, hemiretinal vein occlusion, and central retinal vein occlusion depending on the occlusion site. Risk factors for the development of a retinal vein occlusion include diabetes mellitus, hypertension, hyperlipidemia, atherosclerosis, glaucoma, and smoking. ${ }^{2}$

The clinical course and visual prognosis of retinal vein occlusions can be highly variable. Clinical trials have evaluated treatment modalities including observation, laser, intravitreal triamcinolone, and anti-vascular endothelial growth factor (VEGF) therapy. Intravitreal bevacizumab, an anti-VEGF drug, has been used to treat a variety of vitreoretinal diseases. Rosenfeld et al first injected intravitreal bevacizumab for macular edema from a central retinal vein occlusion and also reported long-term improvements in visual acuity and optical coherence tomography (OCT, Carl Zeiss Meditec, Jena, Germany) being sustained through one year with treatment., ${ }^{3,4}$ More recently, randomized, controlled clinical trials have evaluated the frequency of treatment with anti-VEGF therapy for macular edema secondary to retinal vein occlusions to help determine optimal long-term therapeutic strategies. ${ }^{5,6}$

We describe a case of an acute hemiretinal vein occlusion with confluent macular hemorrhage and persistent macular edema for which early and continued treatment with intravitreal bevacizumab facilitated functional and structural improvement and resolution.

\section{Case report}

A 39-year-old male with no significant past medical history presented with decreased vision in the left eye for six weeks. The patient was initially evaluated at an outside facility and diagnosed with a hemiretinal vein occlusion in the left 

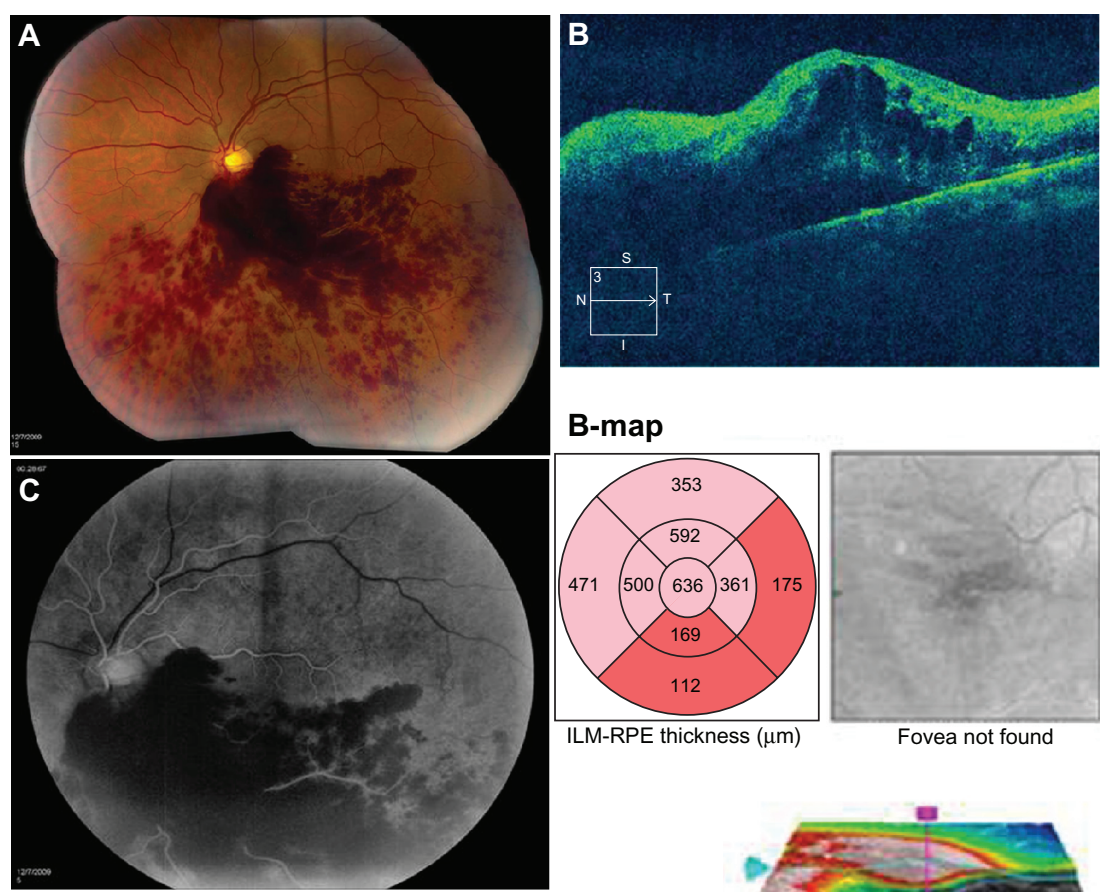

\section{B-map}
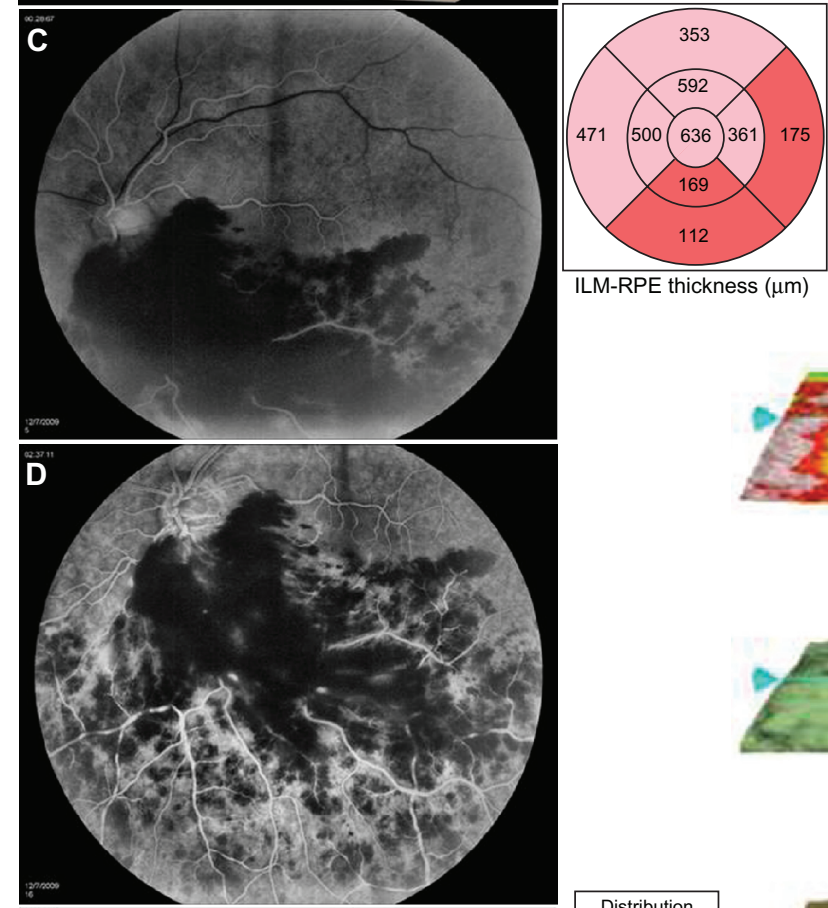

ILM-RPE thickness $(\mu \mathrm{m})$

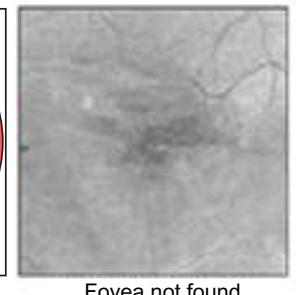

Fovea not found

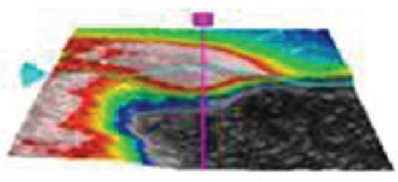

ILM-RPE

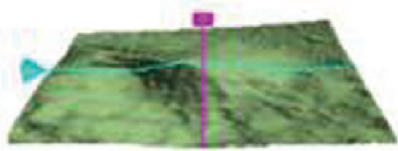

ILM
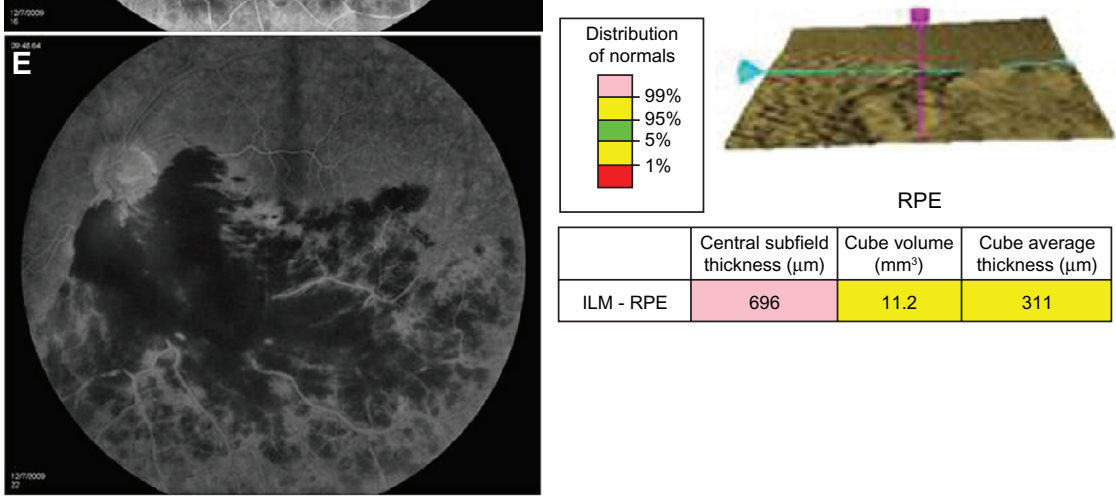

Figure I Initial presentation. Best corrected visual acuity 20/80. (A) Color fundus photograph demonstrates extensive, confluent inferior retinal hemorrhages with macular involvement. (B) Optical coherence tomography demonstrates intraretinal cysts and subretinal fluid. Central foveal thickness $696 \mathrm{microns}$ (central I mm subfield). (C-E) Fluorescein angiography. (C) Early: 28 seconds, (D) 2.37 minutes, and (E) Late: 9.42 minutes, extensive blockage from hemorrhage and late hyperfluorescence.

eye. Medical and hypercoaguable laboratory evaluation was unremarkable, and the patient was referred to the Bascom Palmer Eye Institute. Best corrected visual acuity was $20 / 20$ in the right eye and 20/80 in the left eye. Intraocular pressures were 18 and $17 \mathrm{mmHg}$ in the right and left eye, respectively. External and slit lamp examinations were unremarkable. Fundus evaluation of the right eye was within normal limits, and the left eye demonstrated extensive, confluent intraretinal hemorrhages extending inferiorly from the nerve and involving the macula (Figure 1A). OCT of the right eye was unremarkable, and the left eye demonstrated intraretinal 
and subretinal fluid with a central retinal thickness of 696 microns (Figure 1B). Fluorescein angiography of the left eye showed blockage from hemorrhage, with subsequent limited assessment of perfusion and late hyperfluorescence (Figure 1C-E). The patient was treated with $1.25 \mathrm{mg}$ of intravitreal bevacizumab at this visit. At one month, visual acuity in the left eye improved to $20 / 60$ and OCT demonstrated improved fluid with a central retinal thickness of 534 microns (Figure 2A). The patient was retreated with intravitreal bevacizumab. At the subsequent four-week visit, the patient was symptomatic with a decline in visual acuity to 20/70 and increased fluid was present on OCT (Figure 2B). The patient was treated with a third intravitreal bevacizumab injection. Six weeks later, visual acuity improved to $20 / 40$, the confluent macular hemorrhage had improved, and OCT showed reduced fluid (Figure 2C and D). Treatment was continued at this visit, and at six-week intervals due to persistent visual symptoms and macular edema and hemorrhage. The patient received a total of nine intravitreal bevacizumab injections. At recent follow-up, six weeks after the last injection, visual acuity improved to $20 / 25$ and fundus evaluation showed minimal intraretinal hemorrhages (Figure 3A). OCT demonstrated a preserved foveal contour with resolved fluid and subfoveal inner and outer segment (IS/OS) disruption (Figure 3B). The patient was observed.
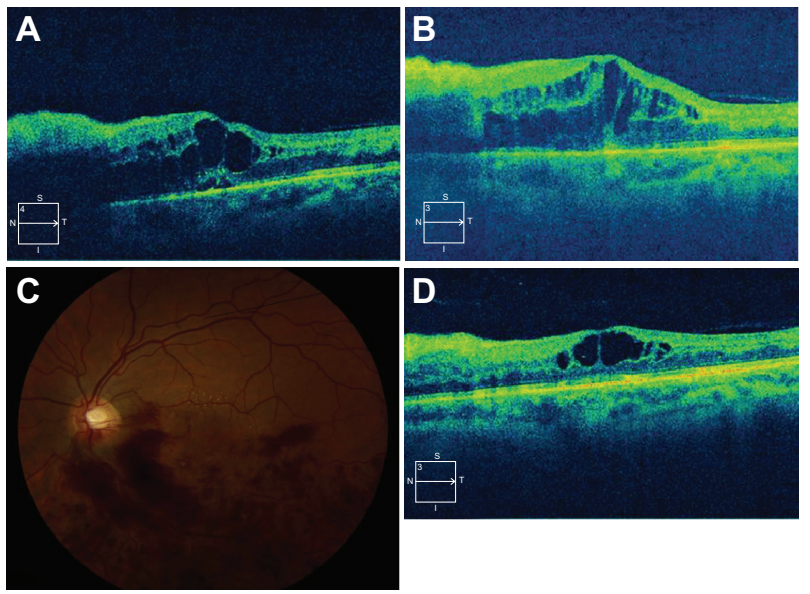

Figure 2 Cirrus spectral domain optical coherence tomography progression. (A) Best corrected visual acuity $20 / 60$, improved intraretinal and subretinal fluid (central foveal thickness 534 microns) after initial intravitreal bevacizumab injection four weeks earlier. (B) Best corrected visual acuity 20/70, central foveal thickness 682 microns. (C) Color fundus photograph six weeks after third intravitreal bevacizumab injection. Improved confluent macular hemorrhage. (D) Best corrected visual acuity 20/40, central foveal thickness 473 microns, corresponding optical coherence tomography to $(\mathbf{C})$ visit.
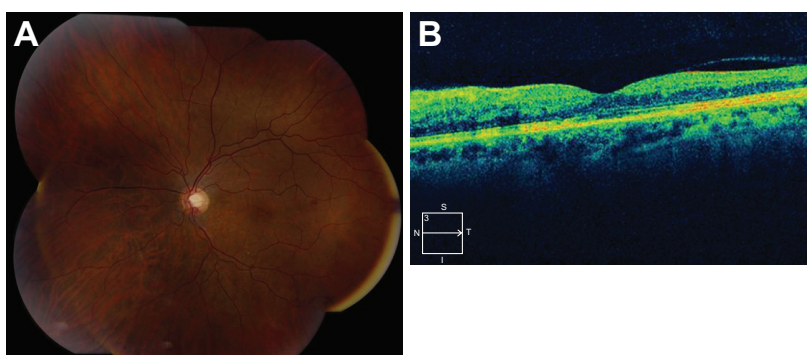

Figure 3 Recent follow-up. Best corrected visual acuity 20/25. (A) Color fundus photograph demonstrates resolution of majority of confluent hemorrhages. (B) Optical coherence tomography demonstrates resolved fluid (central foveal thickness $26 \mathrm{I}$ microns) and presence of subfoveal inner and outer segment disruption.

\section{Discussion}

Macular edema is often a frequent cause of vision loss in patients with retinal vein occlusions. Since hemiretinal vein occlusions share etiologic and clinical features of both branch and central retinal vein occlusions, treatment strategies are often extrapolated from studies pertaining to these conditions. The Branch Vein Occlusion Study (BVOS) reported that laser photocoagulation is beneficial for perfused macular edema with $<20 / 40$ vision for at least three months, but the visual recovery is both slow and limited. ${ }^{7}$ After three years of follow-up, $63 \%$ of laser treated eyes improved $\geq 2$ lines of vision compared with $36 \%$ of control eyes. ${ }^{7}$ The average improvement of visual acuity was only 1.3 lines from the baseline in the laser-treated group, and $40 \%$ of eyes had a visual acuity of $\leq 20 / 40$ and $12 \%$ had a visual acuity of $<20 / 200 .{ }^{7}$ Based on the Central Retinal Vein Occlusion Study (CVOS) results, grid laser photocoagulation is not a recommended therapy for improving visual acuity from macular edema secondary to central retinal vein occlusion. ${ }^{8}$ The Standard Care versus Corticosteroid for Retinal Vein Occlusion (SCORE) study group concluded that $1 \mathrm{mg}$ intravitreal triamcinolone, with retreatment criteria as utilized in the trial, was superior to observation and could be considered up to one year for central retinal vein occlusion-related macular edema, and was

Table I Branch retinal vein occlusion summary data ${ }^{5,9,10}$

\begin{tabular}{lllll}
\hline Treatment & Months & $\begin{array}{c}\text { BCVA } \\
\text { change }^{\mathrm{a}}\end{array}$ & $\geq \mathbf{I 5}$ letters $^{\mathrm{a}}$ & $\begin{array}{l}\text { CFT } \\
\text { change }\end{array}$ \\
\hline $\begin{array}{l}\text { Triamcinolone } \\
\text { I mg (SCORE) }\end{array}$ & 12 & +5.7 & $26 \%$ & -149 microns \\
$\begin{array}{l}\text { Dexamethasone } \\
0.7 \mathrm{mg} \text { (GENEVA) }\end{array}$ & 6 & +7.4 & $22 \%$ & -119 microns \\
$\begin{array}{l}\text { Ranibizumab } \\
0.5 \mathrm{mg} \text { (BRAVO) }\end{array}$ & 12 & +18.3 & $60 \%$ & -347 microns \\
\hline
\end{tabular}

Abbreviations: BCVA, best corrected visual acuity; CFT, central foveal thickness. 
Table 2 Central retinal vein occlusion summary data ${ }^{6,9,10}$

\begin{tabular}{lllll}
\hline Treatment & Months & $\begin{array}{l}\text { BCVA } \\
\text { change }^{\mathbf{a}}\end{array}$ & $\geq 15$ letters $^{\mathrm{a}}$ & $\begin{array}{l}\text { CFT } \\
\text { change }\end{array}$ \\
\hline $\begin{array}{l}\text { Triamcinolone } \\
\text { I mg (SCORE) }\end{array}$ & 12 & -1.2 & $27 \%$ & -196 microns \\
$\begin{array}{l}\text { Dexamethasone } \\
0.7 \mathrm{mg} \text { (GENEVA) }\end{array}$ & 6 & +0.1 & $22 \%$ & -119 microns \\
$\begin{array}{l}\text { Ranibizumab } \\
0.5 \mathrm{mg} \text { (CRUISE) }\end{array}$ & 12 & +13.9 & $51 \%$ & -462 microns \\
\hline
\end{tabular}

Note: aETDRS letters.

Abbreviations: BCVA, change in best corrected visual acuity; CFT, change in central foveal thickness; EDTRS, Early Treatment for Diabetic Retinopathy Study.

equivalent to macular grid laser treatment for macular edema from a branch retinal vein occlusion (Tables 1 and 2). ${ }^{9,10}$ This was the first trial to demonstrate efficacy of a treatment for macular edema secondary to a central retinal vein occlusion. Further, the Ozurdex Geneva Study Group investigated the efficacy of a dexamethasone intravitreal implant, Ozurdex ${ }^{\circledR}$, for the treatment of macular edema due to retinal vein occlusions. The proportion of eyes achieving at least a 15-letter improvement from baseline was significantly greater in the $0.35 \mathrm{mg}$ and $0.7 \mathrm{mg}$ implant groups from day 30; but this effect was not maintained by day 180 , when no statistically significant difference from the sham group was observed (Tables 1 and 2) ${ }^{11}$ However, associated risks of intraocular pressure elevation and cataracts with steroid treatment were present in both studies.

Additional therapeutic modalities have also been explored in the treatment of macular edema from retinal vein occlusions. VEGF-A has been implicated as a major factor for increased vascular permeability, and elevated intravitreal VEGF levels have been reported to be significantly increased after retinal vein occlusions and correlate with the degree of macular edema. ${ }^{12}$ VEGF also stimulates endothelial cell hypertrophy, which reduces capillary lumen size and may lead to retinal ischemia. ${ }^{13}$ Bevacizumab is a full length monoclonal humanized antibody to all active isoforms of vascular endothelial growth factor, and is frequently used in clinical practice to treat macular edema from retinal vein occlusions. Recently, clinical studies have demonstrated beneficial effects of monthly intravitreal treatment with an anti-VEGF agent, ranibizumab, on both macular edema and visual acuity in patients with retinal vein occlusions. Data from the Phase III Study of the Efficacy and Safety of Ranibizumab Injection in Patients with Macular Edema Secondary to Branch Retinal Vein Occlusion (BRAVO) and the Study of the Efficacy and Safety of Ranibizumab Injection in Patients with Macular Edema Secondary to Central Retinal Vein Occlusion (CRUISE) demonstrated that a higher proportion of patients treated with ranibizumab $0.3 \mathrm{mg}$ and $0.5 \mathrm{mg}$ experienced significant improvements in visual acuity and central foveal thickness at six months following monthly dosing compared with patients who received sham injections (Tables 1, 2, and 3). 5,6 These improvements were sustained at 12 months in both trials in the ranibizumab groups, following six months of as-needed treatment (Table 3). ${ }^{5,6}$ Overall, results from these studies demonstrate that regular, monthly anti-VEGF treatment for retinal vein occlusions provided improvements superior to previous treatment modalities.

In the current report, a young patient with decreased visual acuity and extensive macular hemorrhage with macular edema demonstrated an initial and ongoing functional and structural improvement with continued intravitreal bevacizumab treatment. Initial visual acuity, younger age, duration of retinal vein occlusion, baseline central retinal thickness, response to the first injection, and integrity of the photoreceptors have all been reported to be predictive factors for response to anti-VEGF therapy. ${ }^{14,15}$ Although this patient returned to his baseline vision, the presence of subfoveal IS/OS disruption likely secondary to chronic macular edema and/or initial hemorrhage may also indicate that ongoing treatment with intravitreal bevacizumab prevented further destructive changes and a subsequent decline in vision. The Patterns and Trends Survey by the American Society of Retina Specialists showed that approximately $50 \%$ of respondents use intravitreal bevacizumab as first-line therapy for retinal vein occlusions. ${ }^{16}$

Table 3 Outcomes in BCVA and CFT after 6 and 12 months of ranibizumab $0.5 \mathrm{mg}$ treatment in BRAVO and CRUISE studies ${ }^{5,6}$

\begin{tabular}{|c|c|c|c|c|}
\hline Study & $\begin{array}{l}\text { Mean change from } \\
\text { baseline } B C V A^{a} 0.5 \mathrm{mg} \\
\text { at } 6 \text { months versus sham }\end{array}$ & $\begin{array}{l}\text { Mean change from } \\
\text { baseline CFT, } \mu \mathrm{m} \\
\text { at } 6 \text { months versus sham }\end{array}$ & $\begin{array}{l}\text { Mean change from } \\
\text { baseline BCVA } 0.5 \mathrm{mg} \\
\text { at } 12 \text { months versus sham }\end{array}$ & $\begin{array}{l}\text { Mean change from } \\
\text { baseline CFT, } \mu \mathrm{m} \\
\text { at } 12 \text { months versus sham }\end{array}$ \\
\hline BRAVO & +18.3 versus +7.3 & -345.2 versus -157.7 & +18.3 versus +12.1 & -374.4 versus -273.4 \\
\hline CRUISE & +14.9 versus +0.8 & -452.3 versus -167.7 & +13.9 versus +7.3 & -462.1 versus -427.2 \\
\hline
\end{tabular}

Note: aETDRS letters. Patients were randomized I:I:I to receive sham injections or ranibizumab in one of two doses ( 0.3 or $0.5 \mathrm{mg})$ in both studies.

Abbreviations: BCVA, best corrected visual acuity; CFT, central foveal thickness; ETDRS, Early Treatment for Diabetic Retinopathy Study. 
The favorable treatment outcome for this patient lends support to the clinical impression that regular injections of intravitreal bevacizumab are an effective primary treatment strategy for persistent macular edema and hemorrhage from a hemiretinal vein occlusion.

\section{Acknowledgment}

This research was supported by an unrestricted award from Research to Prevent Blindness (P30EY014801).

\section{Disclosure}

The authors report no conflicts of interest in this work.

\section{References}

1. Rogers S, McIntosh RL, Cheung N, et al. The prevalence of retinal vein occlusion: pooled data from population studies from the United States, Europe, Asia and Australia. Ophthalmology. 2010;117:313-319.

2. Hayreh SS, Zimmerman B, McCarthy MJ, Podhajsky P. Systemic diseases associated with various types of retinal vein occlusion. Am J Ophthalmology. 2001;131:61-77.

3. Rosenfeld PJ, Fung AE, Puliafito CA. Optical coherence tomography findings after an intravitreal injection of bevacizumab (avastin) for macular edema from central retinal vein occlusion. Ophthalmic Surg Lasers Imaging. 2005;36:336-339.

4. Gregori NZ, Gaitan J, Rosenfeld PJ, et al. Long-term safety and efficacy of intravitreal bevacizumab (avastin) for the management of central retinal vein occlusion. Retina. 2008;28:1325-1337.

5. Campochiaro PA, Heier JS, Feiner L, et al. Ranibizumab for macular edema following branch retinal vein occlusion: six month primary end point results of a Phase III study. Ophthalmology. 2010;117:1102-1112.

6. Brown DM, Campochiaro PA, Singh RP, et al. Ranibizumab for macular edema following central retinal vein occlusion: six-month primary end points results of a phase III study. Ophthalmology. 2010;117:1124-1133.
7. The Branch Vein Occlusion Study Group. Argon laser photocoagulation for macular edema in the branch vein occlusion. Am J Ophthalmology. 1984:98:271-282.

8. The Central Vein Occlusion Study Group. Evaluation of grid pattern photocoagulation for macular edema in central vein occlusion. The Central Vein Occlusion Study Group M report. Ophthalmology. 1995;102:1425-1433.

9. The SCORE Study Research Group. SCORE study report 5: a randomized trial to compare the efficacy and safety of intravitreal injection(s) of triamcinolone acetonide with standard care to treat vision loss associated with macular edema secondary to central retinal vein occlusion. Arch Ophthalmol. 2009;127:1101-1114.

10. The SCORE Study Research Group. SCORE study report 6: a randomized trial to compare the efficacy and safety of intravitreal injection(s) of triamcinolone acetonide with standard care to treat vision loss associated with macular edema secondary to branch retinal vein occlusion. Arch Ophthalmol. 2009;127:1115-1128.

11. Haller JA, Bandello F, Belfort R, et al. Randomized, sham-controlled trial of dexamethasone intravitreal implant in patients with macular edema due to retinal vein occlusion. Ophthalmology. 2010;117:1134-1146.

12. Funk M, Kriechbaum K, Prager F, et al. Intraocular concentrations of growth factors and cytokines in retina vein occlusion and the effect of therapy with bevacizumab. Invest Ophthalmol Vis Sci. 2009;50:1025-1032.

13. Figueroa MS, Contreras I, Noval S, et al. Results of bevacizumab as the primary treatment for retinal vein occlusion. Br J Ophthalmol. 2010;94:1052-1056.

14. Hoch AE, Ruppenstein M, Ach T, Dithmar S. OCT patterns of macular edema and response to bevacizumab therapy in retinal vein occlusion. Graefes Arch Clin Exp Ophthalmol. 2010;248:1567-1572.

15. Wolf-Schnurrbusch UE, Ghanem R, Rothenbuehler SP, et al. Predictors for short term visual outcome after anti-VEGF therapy of macular edema due to central retinal vein occlusion. Invest Ophthalmol Vis Sci. 2011;52:3334-3337.

16. American Society of Retina Specialists Annual Preferences and Trends Survey, 2009. Available at: http://www.asrs.org. Accessed September 12, 2011.
Clinical Ophthalmology

\section{Publish your work in this journal}

Clinical Ophthalmology is an international, peer-reviewed journal covering all subspecialties within ophthalmology. Key topics include: Optometry; Visual science; Pharmacology and drug therapy in eye diseases; Basic Sciences; Primary and Secondary eye care; Patient Safety and Quality of Care Improvements. This journal is indexed on

Submit your manuscript here: http://www.dovepress.com/clinical-ophthalmology-journal

\section{Dovepress}

PubMed Central and CAS, and is the official journal of The Society of Clinical Ophthalmology (SCO). The manuscript management system is completely online and includes a very quick and fair peer-review system, which is all easy to use. Visit http://www.dovepress.com/ testimonials.php to read real quotes from published authors. 